(9). Other genes are regulated selectively by either LXR (e.g., ABCA1) or SREBP-1c (e.g., FAS). Dietary polyunsaturated fatty acids suppress both LXR and SREBP-1c but are also crucial to StAR expression (6). It is notable that the proteolytic activation of SREBP-1c, unlike that of other SREBPs, is regulated by insulin and probably not suppressed by cholesterol (10).

Little is known about the physiological ligands for LXR. However, there is evidence that mitochondrial cholesterol metabolism may be a source of these activators. StAR may therefore also participate as an activator of LXR activity. The steroid intermediate 22R-hydroxycholesterol, which is formed by CYP11A1, is a potent LXR agonist but is unlikely to be released from the mitochondrial cholesterol-cleavage process. However, StAR can also mediate cholesterol transfer to mitochondrial cholesterol hydroxylases that may generate LXR agonists. Other members of the StAR family - StARD4 and StARD5 - exhibit cholesterol transfer activity in steroidogenic cells and macrophages, respectively (11). Interestingly, elevation of these StAR relatives (and perhaps also of StAR) causes LXR activation, possibly by forming a hydroxysterol agonist. Hydroxysterols also stimulate StAR expression in steroidogenic cells (12), possibly through this new LXR mechanism.

This connection between LXR and StAR, introduced in this issue of the JCI by Cummins et al. (5), provides a new avenue for regulation of steroid synthesis. This may extend to other steroidogenic processes, including testosterone synthesis in the Leydig cells of the testis, estrogens in the ovary, and even neurosteroids produced in glial cells of the brain, each of which utilize StAR. It should be noted that cholesterol homeostasis in human adrenals is primarily mediated by LDL rather than HDL (13). It remains to be determined whether the LXR gateway to StAR and steroid synthesis remains open in tissues where cholesterol fluxes are less than in the adrenal or when the LDL pathway partially bypasses the lipid droplets (see Figure 1).

Address correspondence to: Colin R. Jefcoate, Department of Pharmacology, University of Wisconsin Medical School, 1300 University Avenue, Madison, Wisconsin 53711, USA. Phone: (608) 263-3975; Fax: (608) 262-1257; E-mail:Jefcoate@wisc.edu.

1. Zelcer, N., and Tontonoz, P. 2005. Liver X receptors as integrators of metabolic and inflammatory signaling. J. Clin. Invest. 116:607-614. doi:10.1172/ JCI27883.
2. Jefcoate, C. 2002. High-flux mitochondrial cholesterol trafficking, a specialized function of the adrenal cortex. J. Clin. Invest. 110:881-890. doi:10.1172/ JCI200216771.

3. Stocco, D.M. 2001. StAR protein and the regulation of steroid hormone synthesis. Annu. Rev. Physiol. 63:193-213.

4. Fu, Y., et al. 2004. Expression of caveolin-1 enhances cholesterol efflux in hepatic cells. J. Biol. Chem. 279:14140-14146.

5. Cummins, C.L., et al. 2006. Liver X receptors regulate adrenal cholesterol balance. J. Clin. Invest. 116:1902-1912. doi:10.1172/JCI28400.

6. Stocco, D.M., et al. 2005. Multiple signaling pathways regulating steroidogenesis and StAR expression: more complicated than we thought. Mol. Endocrinol. 19:2647-2659.

7. Ishii, T., et al. 2002. The roles of circulating highdensity lipoproteins and trophic hormones in the phenotype of knockout mice lacking the steroidogenic acute regulatory protein. Mol. Endocrinol. 16:2297-2309.

8. Shea-Eaton, W.K., et al. 2001. Sterol regulatory element-binding protein-1a regulation of the steroidogenic acute regulatory protein gene. Endocrinology. 142:1525-1533.

9. Sampath, H., and Ntambi,J.M. 2005. Polyunsaturated fatty acid regulation of genes of lipid metabolism. Annu. Rev. Nutr. 25:317-340.

10. Hegarty, B.D., et al. 2005. Distinct roles of insulin and LXR in the induction and cleavage of SREBP-1c. Proc. Natl. Acad. Sci. U. S. A. 102:751-796.

11. Soccio, R.E., et al. 2005. Differential gene regulation of StARD4 and StARD5 cholesterol transfer proteins. J. Biol. Chem. 280:19410-19418.

12. King, S.R., et al. 2004. Oxysterols regulate expression of the StAR protein. J. Mol. Endocrinol. 32:507-517.

13. Strauss, J.F., et al. 2003. START domain proteins and the intracellular trafficking of cholesterol in steroidogenic cells. Mol. Cell. Endocrinol. 202:59-65.

\title{
New insights into the regulation of inflammation by adenosine
}

\author{
Joel Linden \\ Department of Medicine and Cardiovascular Research Center, University of Virginia, Charlottesville, Virginia, USA.
}

\begin{abstract}
Adenosine, long known as a regulator of cardiovascular function, has recently been identified as a significant paracrine inhibitor of inflammation that acts primarily by activation of $A_{2 A}$ adenosine receptors $\left(A_{2 A} A R s\right)$ on lymphoid or myeloid cells. In this issue of the JCI, Yang et al. describe a proinflammatory phenotype resulting from deletion of the gene encoding the $A_{2 B}$ adenosine receptor $\left(A_{2 B} A R\right)$ in the mouse, suggesting that activation of the $A_{2 B} A R$ can also have antiinflammatory effects (see the related article beginning on page 1913). Nevertheless, the role of the $A_{2 B} A R$ remains enigmatic since its activation can either stimulate or inhibit the release of proinflammatory cytokines in different cells and tissues.
\end{abstract}

Nonstandard abbreviations used: $\mathrm{A}_{2 \mathrm{~A}} \mathrm{AR}, \mathrm{A}_{2 \mathrm{~A}}$ adenosine receptor; $\mathrm{A}_{2 \mathrm{~B}} \mathrm{AR}, \mathrm{A}_{2 \mathrm{~B}}$ adenosine receptor.

Conflict of interest: The author owns stock in Adenosine Therapeutics, LLC.

Citation for this article: J. Clin. Invest. 116:1835-1837 (2006). doi:10.1172/JCI29125.
There is growing interest in elucidating the mechanisms by which adenosine inhibits the immune system, since these inhibitory adenosine receptors and their downstream signaling pathways are promising targets for new antiinflammatory therapies. By signaling through the $A_{2 A}$ adenosine receptor $\left(\mathrm{A}_{2 \mathrm{~A}} \mathrm{AR}\right)$, adenosine suppresses the immune system, primarily by inhibiting lymphoid or myeloid cells including neutrophils (1), macrophages (2), lymphocytes $(3,4)$, and platelets (5). These responses are amplified by rapid induction of $\mathrm{A}_{2 \mathrm{~A}} \mathrm{AR}$ mRNA in macrophages and $\mathrm{T}$ lymphocytes in response to inflammatory or ischemic stimuli $(2,3$, $6,7)$. The $A_{2 B}$ adenosine receptor $\left(A_{2 B} A R\right)$ also appears to mediate antiinflammatory effects in macrophages by inhibiting the production of TNF- $\alpha$ and IL-1 $\beta$, stimulating IL-10 and inhibiting macrophage proliferation (8-11) (Figure 1A). Macrophage $A_{2 B} A R$ signaling increases during 
Table 1

Proinflammatory effects of activating $A_{2 B} R$

\section{Cell}

Mast cell

Bronchial smooth muscle

Intestinal epithelial cell

Astroglioma

Astrocytoma; astrocyte

Osteoblast

Lung fibroblast

Pituitary folliculostellate cell

Airway epithelial cell

$\begin{array}{cc}\text { Response } & \text { References } \\ \text { Degranulation, IL-8 release } & 22-24 \\ \text { IL-6 and MCP-1 release } & 25 \\ \text { IL-6 release } & 26 \\ \text { IL-6 release } & 27 \\ \text { IL-6 release } & 27-29 \\ \text { IL-6 release } & 30 \\ \text { IL-6 release } & 31 \\ \text { IL-6 release } & 32 \\ \text { Prostenoid release } & 33\end{array}$

MCP-1, monocyte chemoattractant protein 1.

inflammation, as the macrophage-activating cytokine IFN- $\gamma$ causes induction of macrophage $A_{2 B} A R$ mRNA (12). However, the $\mathrm{A}_{2 \mathrm{~B}} \mathrm{AR}$ is somewhat unusual in that it is dually coupled to the generally antiinflammatory $G$ protein $G_{s}$ and the generally proinflammatory $G$ protein $G_{q}$ (13); in addition, numerous proinflammatory effects mediated by activation of the $\mathrm{A}_{2 \mathrm{~B}} \mathrm{AR}$ have also been described (Table 1).

\section{Inflamed phenotype of the $A_{2 B} A R$ knockout mouse}

Given the opposing cellular effects mediated by $\mathrm{A}_{2 \mathrm{~B}} \mathrm{AR}$ activation, the phenotype that would result from deletion of the gene encoding $\mathrm{A}_{2 \mathrm{~B}} \mathrm{AR}$ was uncertain. In this issue of the JCI, Yang and coworkers use a receptor knockout/reporter gene knock-in approach to confirm the expected expression pattern of the $\mathrm{A}_{2 \mathrm{~B}} \mathrm{AR}$ transcript, noting high levels in monocytes/ macrophages and the vasculature (14). Interestingly, they report a moderately inflamed phenotype in the $\mathrm{A}_{2 \mathrm{~B}} \mathrm{AR}$ knockout mouse at baseline, including elevated adhesion molecule expression on vascular endothelial cells and elevated cytokine production. The inflammatory phenotype is exaggerated in mice given endotoxin. The baseline response to $\mathrm{A}_{2 \mathrm{~B}} \mathrm{AR}$ knockout is surprising since the $A_{2 B} A R$ is recognized to have a low affinity for adenosine, yet the data imply that baseline adenosine levels are high enough to produce some activation of the $A_{2 B} A R$. A well-recognized limitation of the global knockout approach is that the resulting phenotype may reflect a developmental adaptation to the gene knockout and not an acute direct consequence of deleting the gene product. In order to address this possibility, Yang et al. examined the effect of deleting the gene that codes for $\mathrm{A}_{2 \mathrm{~B}} \mathrm{AR}$ on mRNA levels of the other adenosine receptor subtypes and found no changes. However, other possible adaptations have yet to be examined. It has recently been demonstrated that hypoxia triggers coordinate upregulation on endothelial cells of mRNA for the $\mathrm{A}_{2 \mathrm{~B}} \mathrm{AR}$ and ectoenzymes involved in the conversion of extracellular adenine nucleotides to adenosine (15) (Figure 1B). In addition, the release of adenine nucleotides from various cells, including neutrophils and endothelial cells, is a regulated process (16). It will be of interest in future studies to determine whether deletion of the gene encoding $\mathrm{A}_{2 \mathrm{~B}} \mathrm{AR}$ influences either nucleotide release or extracellular nucleotide metabolism. Such effects could indirectly influence inflammation by altering the availability of adenosine to other adenosine receptor subtypes, particularly the $\mathrm{A}_{2 \mathrm{~A}} \mathrm{AR}$. Deletion of either the ecto-apyrase CD39 (also known as NTPDase1; ref. 17) or the ecto- $5^{\prime}$-nucleotidase (also known as CD73; refs. 18, 19) results in a proinflammatory phenotype.

\section{Future questions}

It will also be of interest in future studies to examine the response of the $\mathrm{A}_{2 \mathrm{~B}} \mathrm{AR}$

\section{A Macrophage}

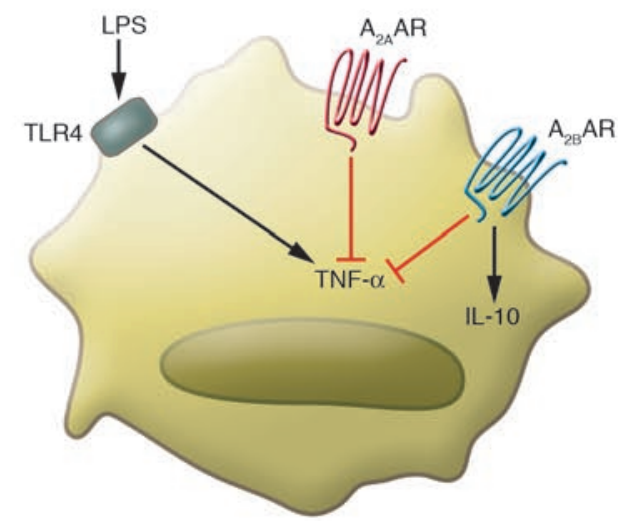

\section{B Endothelial cell}

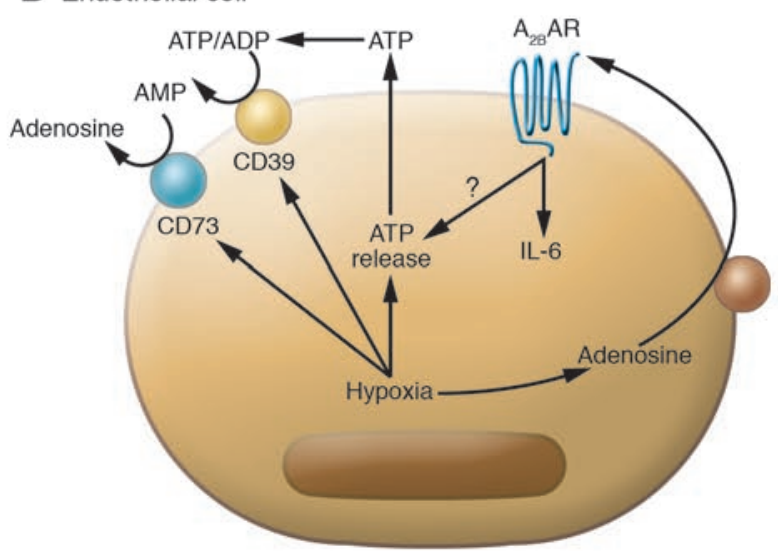

\section{Figure 1}

Anti- and proinflammatory effects mediated by activation of the $A_{2 B} A R$. (A) In macrophages, the release of TNF- $\alpha$ and other proinflammatory cytokines is inhibited as a result of activating either the $A_{2 A} A R$ or the $A_{2 B} A R$. These effects are amplified if TNF- $\alpha$ production is stimulated by LPS, which signals through TLR4 and other Toll-like receptors. Activation of the $A_{2 B} A R$ also stimulates production of the antiinflammatory cytokine IL-10. (B) In endothelial cells and other cells noted in Table 1, activation of the $A_{2 B} A R$ stimulates IL-6 and other proinflammatory cytokines. Hypoxia increases the intracellular production of adenosine, which is transported outside the cell by nucleoside transport proteins. Hypoxia and possibly activation of the $A_{2 B} A R$ stimulate the release of ATP and the production of the $A_{2 B} A R$ and ectoenzymes (CD39 and CD73) that convert ATP to adenosine. Vasodilation in response to $A_{2 B} A R$ activation may increase shear stress to stimulate ATP release. 
knockout mouse in the setting of hypoxia or ischemia, which elicit the accumulation of large levels of adenosine. A selective $\mathrm{A}_{2 \mathrm{~B}} \mathrm{AR}$ antagonist blocks myocardial preconditioning when applied to the isolated rabbit heart after ischemia (20). This could occur either because $A_{2 B} A R s$ on the heart mediate cardioprotection or, as discussed above, because $\mathrm{A}_{2 \mathrm{~B}} \mathrm{AR}$ activation facilitates the release and/or metabolism of adenine nucleotides to indirectly enhance adenosine production. The latter scheme is consistent with the observation that myocardial preconditioning has a remote adenosine-mediated effect on platelet function (21).

In conclusion, the study by Yang et al. (14) bolsters the conclusion that activation of $\mathrm{A}_{2 \mathrm{~B}} \mathrm{ARs}$ on certain cells, particularly macrophages, inhibits inflammation. A proinflammatory phenotype noted at rest is somewhat unexpected, and the mechanism underlying this inflammation is not yet known. In view of a number of previous reports indicating that $\mathrm{A}_{2 \mathrm{~B}} \mathrm{AR}$ activation can be proinflammatory (Table 1), it will be of interest to use the newly available $\mathrm{A}_{2 \mathrm{~B}} \mathrm{AR}$ knockout mouse in order to determine whether $\mathrm{A}_{2 \mathrm{~B}} \mathrm{AR}$ activation on different cells can elicit both pro- and antiinflammatory responses.

Address correspondence to: Joel Linden, Department of Medicine and the Cardiovascular Research Center, MR5 Box 801394, University of Virginia, Charlottesville, Virginia 22908, USA. Phone: (434) 924-5600; Fax: (434) 924-2828; E-mail: jlinden@virginia.edu.

1. Fredholm, B.B. 1997. Purines and neutrophil leukocytes. Gen. Pharmacol. 28:345-350.

2. Murphree, L.J., Sullivan, G.W., Marshall, M.A., and Linden, J. 2005. Lipopolysaccharide rapidly modifies adenosine receptor transcripts in murine and human macrophages: role of NF-kappaB in $\mathrm{A}(2 \mathrm{~A})$ adenosine receptor induction. Biochem. J. 391:575-580.

3. Lappas, C.M., Rieger, J.M., and Linden, J. 2005. A2A adenosine receptor induction inhibits IFN-gamma production in murine CD4+ T cells. J. Immunol. 174:1073-1080.

4. Koshiba, M., Rosin, D.L., Hayashi, N., Linden,
J., and Sitkovsky, M.V. 1999. Patterns of A2A extracellular adenosine receptor expression in different functional subsets of human peripheral T cells. Flow cytometry studies with anti-A2A receptor monoclonal antibodies. Mol. Pharmacol. 55:614-624.

5. Varani, K., Gessi, S., Dalpiaz, A., and Borea, P.A. 1996. Pharmacological and biochemical characterization of purified $\mathrm{A} 2 \mathrm{a}$ adenosine receptors in human platelet membranes by [3H]-CGS 21680 binding. Br. J. Pharmacol. 117:1693-1701.

6. Toufektsian, M.C., et al. 2006. Stimulation of A2A-adenosine receptors after myocardial infarction suppresses inflammatory activation and attenuates contractile dysfunction in the remote left ventricle. Am. J. Physiol. Heart Circ. Physiol. 290:H1410-H1418.

7. Napieralski, R., Kempkes, B., and Gutensohn, W. 2003. Evidence for coordinated induction and repression of ecto-5'-nucleotidase $(\mathrm{CD} 73)$ and the A2 a adenosine receptor in a human B cell line. Biol. Chem. 384:483-487.

8. Nemeth, Z.H., et al. 2005. Adenosine augments IL-10 production by macrophages through an $\mathrm{A} 2 \mathrm{~B}$ receptor-mediated posttranscriptional mechanism. J. Immunol. 175:8260-8270.

9. Xaus, J., et al. 1999. Adenosine inhibits macrophage colony-stimulating factor-dependent proliferation of macrophages through the induction of $\mathrm{p} 27 \mathrm{kip}-1$ expression. J. Immunol. 163:4140-4149.

10. Kreckler, L.M., Wan, T.C., Ge, Z.D., and Auchampach, J.A. 2006. Adenosine inhibits tumor necrosis factor-alpha release from mouse peritoneal macrophages via $\mathrm{A} 2 \mathrm{~A}$ and $\mathrm{A} 2 \mathrm{~B}$ but not the $\mathrm{A} 3$ adenosine receptor. J. Pharmacol. Exp. Ther. 317:172-180.

11. Sipka, S., et al. 2005. Adenosine inhibits the release of interleukin-1beta in activated human peripheral mononuclear cells. Cytokine. 31:258-263.

12. Xaus, J., et al. 1999. IFN-gamma up-regulates the A2B adenosine receptor expression in macrophages: a mechanism of macrophage deactivation. J. Immunol. 162:3607-3614.

13. Linden, J., Auchampach, J.A., Jin, X., and Figler, R.A. 1998. The structure and function of A1 and A2B adenosine receptors. Life Sci. 62:1519-1524.

14. Yang, D., et al. 2006. The $A_{2 B}$ adensoine receptor protects against inflammation and excessive vascular adhesion. J. Clin. Invest. 116:1913-1923. doi:10.1172/JCI27933.

15. Eltzschig, H.K., et al. 2003. Coordinated adenine nucleotide phosphohydrolysis and nucleoside signaling in posthypoxic endothelium: role of ectonucleotidases and adenosine A2B receptors. J. Exp. Med. 198:783-796.

16. Burnstock, G. 2006. Purinergic signalling. $\mathrm{Br}$. J. Pharmacol. 147(Suppl. 1):S172-S181.

17. Dwyer, K.M., et al. 2004. Thromboregulatory manifestations in human CD39 transgenic mice and the implications for thrombotic disease and transplantation. J. Clin. Invest. 113:1440-1446. doi:10.1172/ JCI200419560.

18. Koszalka, P., et al. 2004. Targeted disruption of cd73/ecto-5'-nucleotidase alters thromboregulation and augments vascular inflammatory response. Circ. Res. 95:814-821.

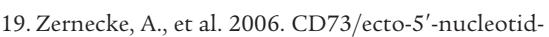
ase protects against vascular inflammation and neointima formation. Circulation. 113:2120-2127.

20. Solenkova, N.V., Solodushko, V., Cohen, M.V., and Downey, J.M. 2006. Endogenous adenosine protects preconditioned heart during early minutes of reperfusion by activating Akt. Am. J. Physiol. Heart Circ. Physiol. 290:H441-H449.

21. Hata, K., Whittaker, P., Kloner, R.A., and Przyklenk, K. 1999. Brief myocardial ischemia attenuates platelet thrombosis in remote, damaged, and stenotic carotid arteries. Circulation. 100:843-848.

22. Ryzhov, S., et al. 2004. Adenosine-activated mast cells induce IgE synthesis by B lymphocytes: an A2B-mediated process involving Th2 cytokines IL-4 and IL-13 with implications for asthma. J. Immunol. 172:7726-7733.

23. Feoktistov, I., Polosa, R., Holgate, S.T., and Biaggioni, I. 1998. Adenosine A2B receptors: a novel therapeutic target in asthma? Trends Pharmacol. Sci. 19:148-153.

24. Auchampach, J.A., Jin, X., Wan, T.C., Caughey, G.H., and Linden, J. 1997. Canine mast cell adenosine receptors: cloning and expression of the A3 receptor and evidence that degranulation is mediated by the A2B receptor. Mol. Pharmacol. 52:846-860.

25. Zhong, H., et al. 2004. A(2B) adenosine receptors increase cytokine release by bronchial smooth muscle cells. Am. J. Respir. Cell Mol. Biol. 30:118-125.

26. Sitaraman, S.V., et al. 2001. Neutrophil-epithelial crosstalk at the intestinal lumenal surface mediated by reciprocal secretion of adenosine and IL- 6 . J. Clin. Invest. 107:861-869.

27. Fiebich, B.L., et al. 1996. Adenosine A2b receptors mediate an increase in interleukin (IL)- 6 mRNA and IL-6 protein synthesis in human astroglioma cells. J. Neurochem. 66:1426-1431.

28. Fiebich, B.L., et al. 2005. IL-6 expression induced by adenosine A2b receptor stimulation in U373 MG cells depends on p38 mitogen activated kinase and protein kinase C. Neurochem. Int. 46:501-512.

29. Schwaninger, M., Neher, M., Viegas, E., Schneider, A., and Spranger, M. 1997. Stimulation of interleukin- 6 secretion and gene transcription in primary astrocytes by adenosine. J. Neurochem. 69:1145-1150.

30. Evans, B.A., et al. 2006. Human osteoblast precursors produce extracellular adenosine, which modulates their secretion of IL- 6 and osteoprotegerin. J. Bone Miner. Res. 21:228-236.

31. Zhong, H., Belardinelli, L., Maa, T., and Zeng, D. 2005. Synergy between A2B adenosine receptors and hypoxia in activating human lung fibroblasts. Am. J. Respir. Cell Mol. Biol. 32:2-8.

32. Rees, D.A., et al. 2003. Adenosine-induced IL-6 expression in pituitary folliculostellate cells is mediated via A2b adenosine receptors coupled to PKC and p38 MAPK. Br. J. Pharmacol. 140:764-772.

33. Li, Y., Wang, W., Parker, W., and Clancy, J.P. 2006. Adenosine regulation of cystic fibrosis transmembrane conductance regulator through prostenoids in Airway epithelia. Am. J. Respir. Cell Mol. Biol. 34:600-608. 